VI.

\title{
Low Implantation of Placenta with Tough Membranes, Causing Prolonged First Stage of Labour in Primiparæ.
}

\author{
By Kedarnath Das, M.D., \\ Teacher of Midwoifery, Campbell Medical School, Calcutta.
}

Case I. A Bengalee female, æt. 15, primipara, started in labour on the afternoon of 23rd November, 1907. On the morning of the 24th midwife was called in, who examined her and found the os dilated to admit two fingers. The pains were strong. I saw her on the morning of the 25th, and was told by the midwife that labour bad not progressed during the previous 24 hours. The pains were strong and coming on every fow minutes. The patient had had practically no sleep during the night, and had an anxious look and a rapid pulse. She begged to be relieved. The os now could admit three fingers with difficulty. The head was low in the pelvis. The os was still soft and fairly dilatable, but had a tendency to cedema. The membranes were tough and did not bulge through the os, but only became tense during a pain. There was very little forewater. I advised rupturing the membranes, which was done at about 8-30 a.m. I was informed that the os dilated fully in about 3 hour's time, and the woman was delivered at 1 p.m.

CASE II. An Armenian lady, æt. 22, primipara, began to have regular labour pains from 3 p.m. on the 18th December, 1907. When the midwife in attendance examined her at 6 p.m., she could just put the tip of her examining finger through the os. The pains, however, were very strong, and came on every few minutes. She was examined again at 11 p.m., when the os was "one finger loose." I was informed immediately afterwards and gave her $30 \mathrm{grs}$. of chloral in two doses without any benefit. The pains continued strong throughout the night, without giving the patient a moment's rest. I saw her at 7 a.m. next morning, i.e., 16 hours after she started in lahour. The patient had an anxious look with a pulse of 112 . The pains were coming on every 3 or 4 minutes. On vaginal examination the head was found low down in the pelvis. The membranes were very thick. No forewaters. In fact, it was with difficulty that the presence of the membranes was detected. The os was two fingers dilated and still soft and dilatable, but the margins were rather thick. I decided to rupture the membranes, and as my finger-nail was of no avail, I used a sharp-pointed pair of scissors. By gently scratching over the fotal scalp, the mem- 
branes were torn without a drop of liquor amnii coming out. This was done at 7-15 a.m. I promised to return by 9 p.m., and when I did so, I learnt that the baby was born at 8-10 a.m. It took the os 16 hours to dilate to two fingers' breadth, and less thar an hour for the remainder of the first stage plus the whole of the second stage. The results speak for themselves. On examining the secundines it was ascertained that the placenta had a low attachment.

These are the typical clinical histories of a number of cases of similar nature which $I$ have observed during the past few years. In all of them-primiparæ,--there was considerable delay in the first stage of labour. In the earlier cases I tried detachment of the membranes from the lower uterine segment, as I thought the delay to be due to adhesion of the membranes. This, however, had no effect until I ruptured the membranes, which were not doing their work. On a close examination of the secundines, the placenta was found to have a low insertion, and this condition was apparentily the chief factor in causing the delay by not allowing the lower uterine segment to retract past the membranes, which were closely applied over the presenting head. When, therefore, the following ccnditions are found to be present, rupturing the membranes will expedite labour. (1) Primipara. (2) Prolonged first stage. (3) Presenting head low in the pelvis. (4) Os, soft, dilatable and generally thin. (5) Very little forewaters. (6) Membranes tough and not bulging through the os during a pain.

Text-books on midwifery do not draw attention to this point. On the other hand, the teaching, that the membranes stould be preserved as long as possible, contributes towards further delay and more suffering. These are the cases where premature rupture of the membranes will help dilatation and expedite labour. 


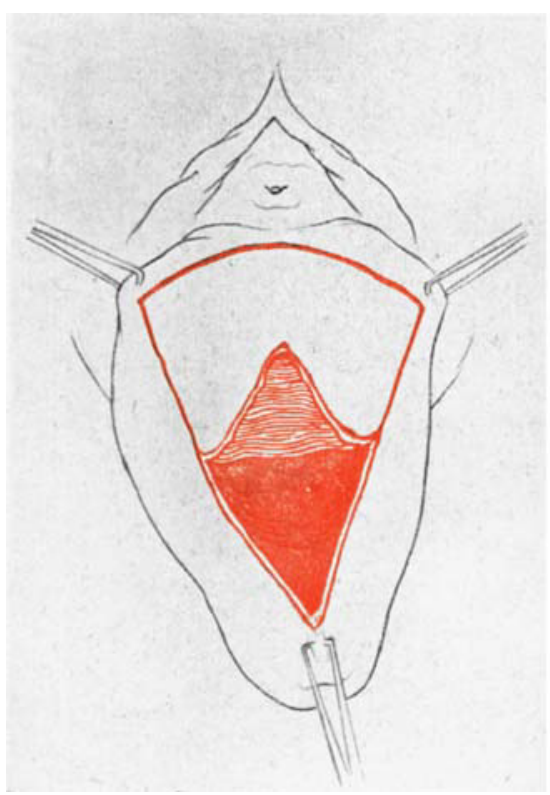

Fig. I. Operation on the anterior wall. Vagina inverted. Flap marked out and partially dissected.

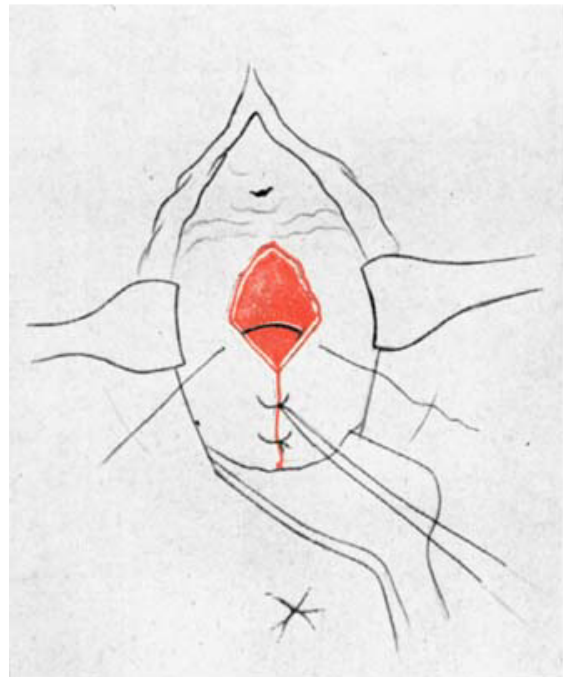

Fig. 3. Uterus has been pushed up. Completion of stitching in anterior wall.

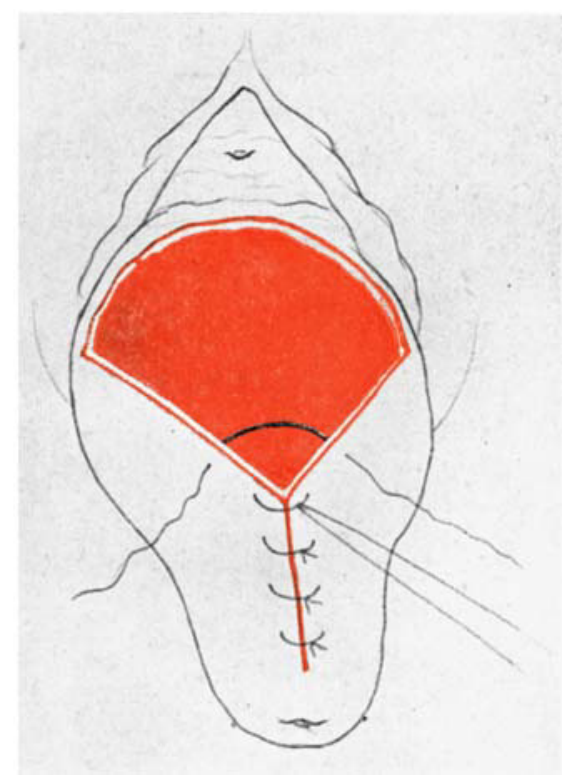

Fig. 2. Dissection completed. First stitches introduced.

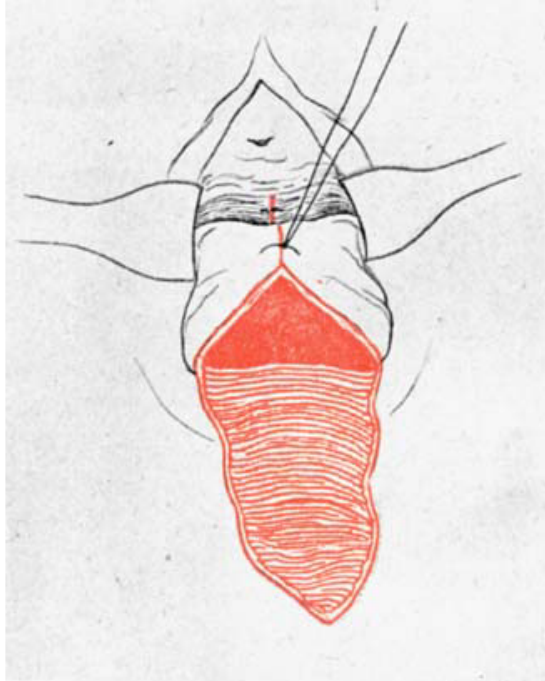

Fig. 4 Posterior wall. Partial dissection of flap. First stitches introduced. 